\title{
Numerical Analysis on Blast Furnace Performance under Operation with Top Gas Recycling and Carbon Composite Agglomerates Charging
}

\author{
Mansheng Chu, Hiroshi Nogami ${ }^{1)}$ and Jun-ichiro Yagi ${ }^{11}$ \\ Graduate Student, Department of Metallurgy, Materials Science and Materials Processing, Graduate School of Engineering, \\ Tohoku University, Aoba-yama 02, Aoba-ku, Sendai, Miyagi-ken 980-8579 Japan. \\ 1) Institute of Multidisciplinary Research for Advanced Materials, Tohoku University, Katahira, Aoba-ku, Sendai, Miyagi-ken \\ 980-8577 Japan.
}

(Received on April 30, 2004; accepted in final form on August 23, 2004)

\begin{abstract}
The blast furnace operations with top gas recycling, carbon composite agglomerates (CCB) charging, cold oxygen blast and waste plastics injection are numerically evaluated by means of multi-fluid blast furnace model on the premise of constant raceway conditions and hot metal temperature. These evaluations are in comparison with conventional operation. Simulation results reveal that CCB charging and/or cold oxygen blast lead to low temperature level in the shaft region, which retards the reduction of CCB. On the other hand, injection of waste plastics enriches hydrogen gas in the furnace. And top gas (after $\mathrm{CO}_{2}$ removal) recycling tremendously enhances the concentrations of $\mathrm{H}_{2}$ and $\mathrm{CO}$ in the whole furnace, which greatly promote the indirect reduction of sinter in shaft despite lower temperature. Under the innovative operations, the efficiency of blast furnace shows evident improvement, especially in the case with simultaneous injections of treated top gas through shaft and tuyere. The model computations predicted that total heat input decreases while the productivity increases under the operation with top gas recycling. Additionally, top gas recycling and waste plastics injection also contribute to considerably reduce carbon dioxide emission. It is expectable to develop high efficiency blast furnace with improved productivity and lowered environment load through exploiting the processes presented in this study. If scrubbing and fixing of $\mathrm{CO}_{2}$ and manufacturing of process oxygen are commercially available, these innovative processes will possess broad applying potential.
\end{abstract}

KEY WORDS: top gas recycling; all oxygen blast; carbon composite agglomerates; waste plastics injection; blast furnace; mathematical model; simulation.

\section{Introduction}

In the past decades, blast furnace process has achieved tremendous progress in the upkeep of long-period and stable operation, pursuance of economical and intensified operation and expansion of blast furnace functions. ${ }^{1)}$ However, the ironmaking system including blast furnace is responsible for large amount of energy consumption. Furthermore, major energy resources are coal and its derivatives. ${ }^{2)}$ The manufacturing and using of coal and coke lead to enormous environment impact, mainly represented by the emission of carbon dioxide. ${ }^{3)}$ In response to build sustainable society, the blast furnace process is faced with large challenge to lower energy consumption and minimize carbon dioxide emission while improving the productivity.

Top gas recycling has been considered as one effective method to improve the blast furnace performance, enhance the utilization of carbon and hydrogen, and reduce the emission of carbon oxides through recirculating the reducing gas components $\left(\mathrm{CO}\right.$ and $\left.\mathrm{H}_{2}\right)$ of top gas into the furnace. Till now, various recycling processes have been sug- gested, numerically evaluated or practically applied for different objectives, mainly including Ohno, ${ }^{4)} \mathrm{HRG}^{3,5)} \mathrm{Qin},{ }^{6}$ ) Fink, ${ }^{7)} \mathrm{Lu}^{8)}$ methods, and so on. These processes distinguish each other by: 1) with $\mathrm{CO}_{2}$ removal or not, 2) with preheating or not, and 3 ) the position of injection.

Regarding HRG method, practical implementation in the blast furnace of RPA Toulachermet (Russia) ${ }^{5}$ ) and model simulations ${ }^{9)}$ have verified that higher productivity while remarkably-lowered reducing agent rate are available if top gas is converted to hot reducing gas (through scrubbing carbon dioxide and reheating to ascertained temperature), and then injected into tuyere accompanied with high oxygenenrichment (over 80\%) blasting. In nature, HRG method doesn't require any basic changes in the conventional blast furnace and its accessories.

A new method of top gas recycling has been proposed, ${ }^{10,11)}$ as shown in Fig. 1. The $\mathrm{CO}_{2}$ in top gas is also separated and fixed considering the injected $\mathrm{CO}_{2}$ gas will increase in-furnace solution loss reaction and thus deteriorate the operation performance. ${ }^{9)}$ For tuyere injection (hereinafter $\mathrm{TI}$ ), the top gas (after $\mathrm{CO}_{2}$ removal) is injected into 

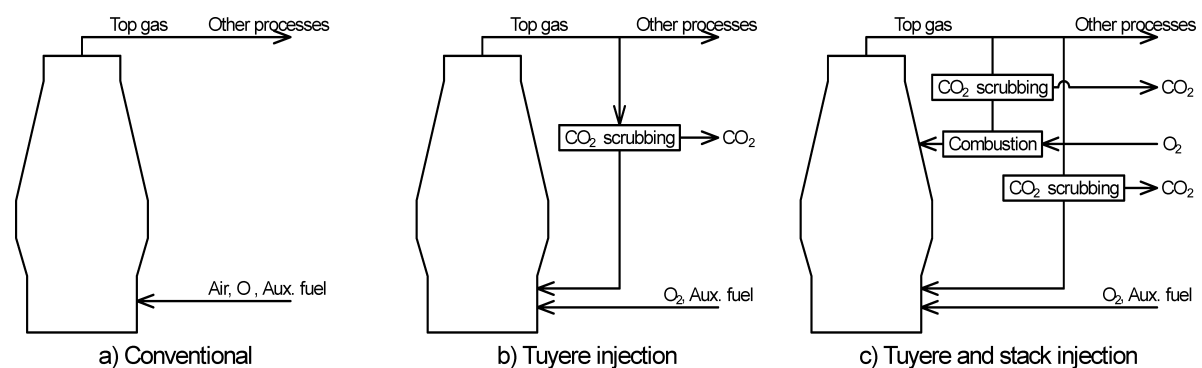

Fig. 1. Methods of top gas recycling considered in this study.

tuyere at ambient temperature. Simultaneously, cold oxygen blast is adopted to intensify the combustion of carbonaceous materials and maintain thermal state of raceway. For shaft injection (SI), the treated top gas is preheated to the ascertained temperature through combusting one part by added oxygen (the added amount of oxygen depends on the preset temperature and shaft injection rate). In addition, waste plastics (PLA) substitute pulverized coal on purpose to ensure the supply of hydrogen and enhance the reuse of waste. Finally, charging carbon composite agglomerates is taken into account to lower the temperature of thermal reserve zone and reduce energy consumption. Essentially, this process is far different from conventional operation and even discards hot stove system.

On basis of improved Rist diagram, several calculations have been carried out for evaluating top gas recycling by this new method. ${ }^{10,11)}$ The results revealed the following advantages with respect to this process, including: 1) the productivity tends to remarkably increase by the relaxation of flooding restriction because blast volume decreases dramatically with all oxygen blast; 2) lower reducing agent rate is available; 3) exhausted carbon can be reduced at great extent due to more involvement of hydrogen in indirect reduction and the fixing of carbon dioxide.

Some technologic problems should be well solved in order to practically implement this innovative process. Firstly, it is necessary to intensify the combustion of carbonaceous materials in raceway due to low oxygen excess ratio and cold blasting. Secondly, it is necessary to realize sequestration and fixing of top gas carbon dioxide effectively and commercially. In order to achieve intensive combustion in raceway, some relevant technologies have been proposed, tested or applied, including new design of gas-oxygen tuyere, ${ }^{5)}$ the improvement in injection lance ${ }^{3)}$ and simultaneous injection of solid/solid or solid/gaseous fuels. ${ }^{11,12)}$ On the other hand, some methods are suggested to separate carbon dioxide from the other components in top gas through solid or liquid adsorptions, for example, PSA (pressure swing adsorption) method1, ${ }^{13)}$ MEA (monoethanolamine) method ${ }^{3,5,13)}$ and so on. Regarding the fixing of carbon dioxide, the proposed methods include: bringing the $\mathrm{CO}_{2}$ into deep sea as dry- $\mathrm{CO}_{2}$-ice blocks, ${ }^{14}$ ) applying to oil production through increasing the flooding efficiency of crude oil by steam- $\mathrm{CO}_{2}$-injection, ${ }^{14)}$ and injection of $\mathrm{CO}_{2}$ together with other carbonaceous materials into electric arc furnace, ${ }^{14)}$ etc. The removal of $\mathrm{CO}_{2}$ does need some extra cost, for example, about $10-20 \$ / \mathrm{t}-\mathrm{CO}_{2}$ by MEA method. ${ }^{10)}$ The relevant pilot trial and process analysis, however, reveal that total production cost of blast furnace is possible to decrease after top gas recycling. ${ }^{1,6)}$ Currently, the process for treating carbon dioxide at low cost and commercial scale is still under development but the possibilities exist. $^{10,14)}$

Although the calculations based on the model of mass and heat balance have been made for the new recycling process, more detailed evaluation is not available yet. Thus, the performance of blast furnace under top gas recycling by the new method is numerically evaluated in this study by means of multi-fluid blast furnace model ${ }^{15-19)}$ presented previously.

Additionally, carbon composite iron ore hot briquette (hereinafter CCB) ${ }^{20)}$ a new type of carbon bearing agglomerates with excellent reduction performance, ${ }^{21)}$ is taken into account to charge into blast furnace.

\section{Evaluation Method and Procedure}

\subsection{Multi-fluid Blast Furnace Model}

In this study, the multi-fluid blast furnace model ${ }^{15,16)}$ of two dimension, steady state and axisymmetry is used to simulate the blast furnace operation with top gas recycling. This blast furnace operation simulator uses multi-fluid dynamics, transport phenomena and reaction as its fundamental framework. The model handles gas, solid, hot metal, molten slag and fine powders as separate phases having different flow mechanisms. The model consists of conservation equations of momentum, thermal energy, chemical species and continuity for all phases, and rate equations of reaction, phase changes and interphase interactions. All governing conservation equations can be expressed by a generalized form.

$$
\operatorname{div}\left(\varepsilon_{i} \rho_{i} u_{i} \psi_{i}-\varepsilon_{i} \Gamma_{\psi_{i}} \operatorname{grad} \psi_{i}\right)=S_{\psi_{i}}
$$

Where variable $\psi$ represents the variables to be solved, including mass, enthalpy, momentum, chemical species and the continuity. The subscript " $i$ " specifies the considered phases. Coefficient $\Gamma_{\psi}$ is the effective diffusivity and source term $S_{\psi}$ takes into account external forces, chemical reactions, phase changes and interphase interactions. The blast furnace is represented by body fitted coordinate system. All conservation equations are transformed according to the coordinate transformation from curvilinear to orthogonal system. The transformed conservation equations are discretized using control volume method and solved simultaneously.

During model evaluations, waste plastics are assumed to consist of combustible component and ash. The composition of combustible component is $\left(\mathrm{CH}_{2}\right)_{n}$ and $n$ is set as 5 . The proximate analysis of the plastics is $70 \%$ volatile matters, $25 \%$ fixed carbon and $5 \%$ ash. Low calorific value of 
plastics is set as $41.9 \mathrm{MJ} / \mathrm{kg}$. Waste plastics are injected into raceway through tuyere. Although combustion performance of waste plastics is a little different from that of pulverized coal, ${ }^{22)}$ the plastics are also treated as fine phase in this study and their reactions are treated following that ${ }^{15)}$ of pulverized coal considering the similarity of their general behaviors in the furnace and unavailable formulations on plastics combustion model.

The behaviors and reactions of $\mathrm{CCB}$ in the furnace follow previous treatments. ${ }^{23)}$

\subsection{Procedure of Analysis}

Totally, four cases are examined in this study. The base case represents the practical convention operation in a blast furnace, where iron bearing burden consists of only sinter, the injectant is pulverized coal and no top gas recycling is considered. Base case is first simulated, and its raceway conditions (mainly including raceway temperature and bosh gas flow rate) and hot metal temperature on slag surface are kept as reference values for the other three cases. In the second case, one part of sinter is replaced by CCB and waste plastics substitute pulverized coal and are injected into tuyere. On basis of the second case, top gas recycling through tuyere injection is adopted in the third case, and simultaneous shaft and tuyere injections are considered in the fourth case.

Before the computations of multi-fluid blast furnace model, raceway conditions are preliminarily estimated on basis of mass and heat balance in raceway. ${ }^{24)}$ In the last three cases, bosh gas flow rate and raceway temperature are simultaneously kept constant as reference values of base case, through adjusting blast temperature, blast rate, enrichment ratio and/or inflow rate of oxygen, and injection rate of plastics and/or recycled top gas. After this, the determined conditions of blast and injections are used as the boundary conditions for the calculations of multi-fluid blast furnace model. Furthermore, throughout the evaluations the hot metal temperature is maintained equivalent through suitably adjusting mass ratio of iron bearing materials (sinter and $\mathrm{CCB}$ ) to coke in the charged burdens.

\section{Results and Discussion}

\subsection{Evaluating Conditions}

The blast furnace analyzed here has hearth diameter of $14.0 \mathrm{~m}$, height of $32.4 \mathrm{~m}$ and inner volume of $4288 \mathrm{~m}^{3}$. Four operation cases of the furnace are numerically evaluated in this study.

The first case stands for conventional operation with no CCB charging and no top gas recycling, which is indexed as base case. Base case is preliminarily simulated and major operation conditions are summarized in Table 1, including blast rate $5698 \mathrm{Nm}^{3} / \mathrm{min}$, blast temperature $1200^{\circ} \mathrm{C}$, oxygen enrichment $8 \%$, coke rate $269 \mathrm{~kg} / \mathrm{thm}$, pulverized coal rate $249 \mathrm{~kg} / \mathrm{thm}$ and productivity $8332 \mathrm{t} / \mathrm{d}$. Note that, these operation parameters have been practically achieved in the reference blast furnace.

The second case is specified as CCB20-PLA, in which twenty percentages of sinter is replaced by $\mathrm{CCB}$ and the conditions of blast and injection include blast temperature $1070^{\circ} \mathrm{C}$, blast rate $5708 \mathrm{Nm}^{3} / \mathrm{min}$, oxygen enrichment $5 \%$,
Table 1. Standard operating conditions of blast furnace as base case.

\begin{tabular}{|ll|c|}
\hline \multicolumn{2}{|c|}{ Item } & Value \\
\hline Blast temperature & {$\left[{ }^{\circ} \mathrm{C}\right]$} & 1200 \\
\hline Blast rate & {$[\mathrm{Nm} / \mathrm{min}]$} & 5698 \\
\hline Oxygen enrichment & {$[\mathrm{mol}-\%]$} & 8.0 \\
\hline PC injection rate & {$[\mathrm{kg} / \mathrm{s}]$} & 24.0 \\
\hline Raceway temperature & {$\left[{ }^{\circ} \mathrm{C}\right]$} & 2197 \\
\hline Bosh gas flow rate & {$\left[\mathrm{Nm}^{3} / \mathrm{min}\right]$} & 8130 \\
\hline Cohesive zone temperature & {$\left[{ }^{\circ} \mathrm{C}\right]$} & $1200-1400$ \\
\hline PC rate & {$[\mathrm{kg} / \mathrm{thm}]$} & 249 \\
\hline Coke rate & {$[\mathrm{kg} / \mathrm{thm}]$} & 269 \\
\hline Productivity & {$[\mathrm{t} / \mathrm{d}]$} & 8332 \\
\hline
\end{tabular}

Table 2. Compositions of iron bearing materials [mass\%].

\begin{tabular}{|c|c|c|c|c|c|c|c|c|}
\hline Item & $\mathrm{Fe}_{2} \mathrm{O}_{3}$ & $\mathrm{Fe}_{3} \mathrm{O}_{4}$ & $\mathrm{FeO}$ & $\mathrm{Fe}$ & $\mathrm{H}_{2} \mathrm{O}$ & $\mathrm{C}$ & Gangue & $\mathrm{C} / \mathrm{O}$ \\
\hline Sinter & 78.57 & 0.00 & 5.94 & 0.00 & 0.19 & 0.00 & 15.30 & -- \\
\hline $\mathrm{CCB}$ & 75.00 & 0.00 & 0.00 & 0.00 & 0.00 & 20.00 & 5.00 & 0.84 \\
\hline
\end{tabular}

Table 3. Compositions of reducing agents [mass $\%$ ].

\begin{tabular}{|c|c|c|c|}
\hline & Volatile matter & Fixed carbon & Ash \\
\hline Coke & 0.0 & 88.5 & 11.5 \\
\hline PC & 18.7 & 72.4 & 8.9 \\
\hline Plastics & 70.0 & 25.0 & 5.0 \\
\hline
\end{tabular}

waste plastics replace pulverized coal with the injection rate of $119 \mathrm{~kg} / \mathrm{thm}$.

The third case with only tuyere injection is indexed as TI, where $\mathrm{CCB}$ charging ratio is also $20 \%$, top gas (after $\mathrm{CO}_{2}$ removal) $2562 \mathrm{Nm}^{3} / \mathrm{min}$ and pure oxygen $2184 \mathrm{Nm}^{3} / \mathrm{min}^{2}$ are simultaneously injected into tuyere at $25^{\circ} \mathrm{C}$ and injection rate of plastics is $128 \mathrm{~kg} / \mathrm{thm}$.

The last case with both shaft injection and tuyere injection is indexed as SI-TI. The conditions of tuyere injection include simultaneous injection of treated top gas $2564 \mathrm{Nm}^{3} / \mathrm{min}$ and pure oxygen $2184 \mathrm{Nm}^{3} / \mathrm{min}$ at $25^{\circ} \mathrm{C}$ besides waste plastics $118 \mathrm{~kg} / \mathrm{thm}$. Regarding shaft injection, the treated top gas is reheated to $900^{\circ} \mathrm{C}$ and the hot gas is injected to shaft location (height $12 \mathrm{~m}$ ) with the rate of $2702 \mathrm{Nm}^{3} / \mathrm{min}$.

The compositions of burdens and injectants adopted in this study are listed in Tables $\mathbf{2}$ and $\mathbf{3}$. The distribution and diameter of charging burdens on burden surface are shown in Fig. 2. The charging ratio of coke is comparatively higher in the regions near central axis and near wall while iron bearing burdens owe higher percentages in radially central region.

The detailed conditions of blast, TI gas, SI gas and injectants are available in Table 4. Note that, the compositions of TI and SI gases are respectively derived from the results of iterative multi-fluid model computations. Throughout the simulations, bosh gas flow rate and raceway temperature are kept constant at $8130 \mathrm{Nm}^{3} / \mathrm{min}$ and $2197^{\circ} \mathrm{C}$.

Additionally, hot metal temperature on slag surface is maintained at $1570^{\circ} \mathrm{C}$ through suitably adjusting the ratio of iron burdens to coke in each case. 


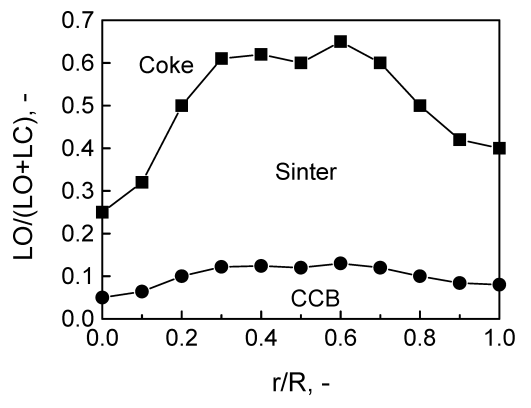

(a) Burden distribution

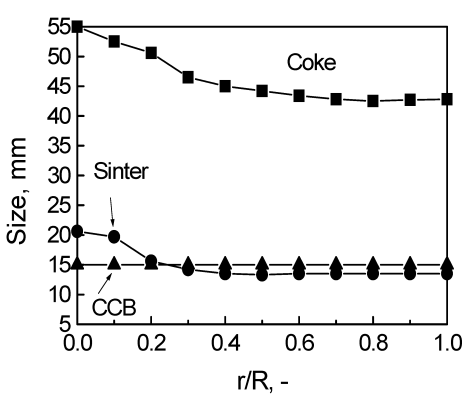

(b) Diameter of charged materials

Fig. 2. Distributions of burdens on burden surface used in this analysis.

Table 4. The conditions of blast, TI gas, SI gas and injectants for each case.

\begin{tabular}{|c|c|c|c|c|c|}
\hline \multicolumn{2}{|r|}{ Item } & Base & CCB20-PLA & $\mathrm{TI}$ & $\mathrm{SI}-\mathrm{TI}$ \\
\hline \multirow{4}{*}{ Blast } & Temp. & 1200 & 1070 & 25 & 25 \\
\hline & Rate $\left[\mathrm{Nm}^{3} / \mathrm{min}\right]$ & 5698 & 5708 & 2184 & 2184 \\
\hline & [mol-\%] & 29 & 26 & 100 & 100 \\
\hline & [mol-\%] & 71 & 74 & 0 & 0 \\
\hline \multirow{4}{*}{$\mathrm{TI}$ gas } & Temp. & -- & -- & 25 & 25 \\
\hline & Rate $\left[\mathrm{Nm}^{3} / \mathrm{min}\right]$ & 0 & 0 & 2562 & 2564 \\
\hline & $\mathrm{CO} \quad[\mathrm{mol}-\%]$ & --- & --- & 66.2 & 67.9 \\
\hline & [mol-\%] & -- & -- & 33.8 & 32.1 \\
\hline \multirow{6}{*}{ SI gas } & Temp. & -- & -- & -- & 900 \\
\hline & Rate $\left[\mathrm{Nm}^{3} / \mathrm{min}\right]$ & 0 & 0 & 0 & 2702 \\
\hline & [mol-\%] & -- & -- & -- & 60.7 \\
\hline & [mol-\%] & -- & -- & -- & 7.2 \\
\hline & [mol-\%] & --- & --- & --- & 28.7 \\
\hline & [mol-\%] & --- & -- & --- & 3.4 \\
\hline \multirow{2}{*}{ Injectant } & Variety & PC & PLA & PLA & PLA \\
\hline & Rate & 24.0 & 10.2 & 13.0 & 13.0 \\
\hline \multicolumn{2}{|c|}{ Raceway temperature $\quad\left[{ }^{\circ} \mathrm{C}\right]$} & \multicolumn{4}{|c|}{2197} \\
\hline \multicolumn{2}{|c|}{ Bosh gas flow rate $\left[\mathrm{Nm}^{3} / \mathrm{min}\right]$} & \multicolumn{4}{|c|}{8130} \\
\hline
\end{tabular}

\subsection{Distributions of Process Variables}

In order to better understand each evaluation case, Fig. 3 shows mass balance of gas for base, CCB20-PLA, TI and SI-TI cases, which is based on the results of model computations and in accordance with the contents in Table 4.

Figure 4 shows the distributions of solid temperature in base, CCB20-PLA, TI and SI-TI cases. In the shaft region of each case, comparatively higher temperature is shown in the regions near central axis and near wall while lower temperature is generated in radially central region. The $\mathrm{W}$-type cohesive zone is formed, which corresponds to charging pattern of burdens described in Fig. 2. Compared with base case, the shaft temperature shows remarkable decrease and cohesive zone shifts downward in CCB20-PLA case, which is attributed to strongly endothermic effects of CCB reduction. In TI case, in-furnace temperature tends to decrease at greater extent from upper to mid zone, cohesive zone is lowered near to deadman zone and steep temperature gradient is formed in the lower zone. The phenomena are elucidated by the following mechanism. At first, in TI case, total heat supply (blast heat and combustion heat) from raceway shows no big difference from base case since bosh gas flow rate and raceway temperature are maintained nearly con- stant. However, in TI case with simultaneous injection of cold oxygen blast and cold top gas, nearly no sensible heat from blast can be available. Additionally, raceway combustions of injected $\mathrm{CO}$ and $\mathrm{H}_{2}$, i.e. $2 \mathrm{CO}(\mathrm{g})+\mathrm{O}_{2} \rightarrow 2 \mathrm{CO}_{2}(\mathrm{~g})$ and $2 \mathrm{H}_{2}(\mathrm{~g})+\mathrm{O}_{2}(\mathrm{~g}) \rightarrow 2 \mathrm{H}_{2} \mathrm{O}(\mathrm{g})$, are exothermic reactions. But the generated $\mathrm{CO}_{2}$ and $\mathrm{H}_{2} \mathrm{O}$ will be instantly converted to $\mathrm{H}_{2}$ and $\mathrm{CO}$ in raceway zone through $\mathrm{C}+\mathrm{CO}_{2} \rightarrow 2 \mathrm{CO}_{2}(\mathrm{~g})$ and $\mathrm{C}+\mathrm{H}_{2} \mathrm{O} \rightarrow \mathrm{H}_{2}(\mathrm{~g})+\mathrm{CO}(\mathrm{g})$. Thus, net calorific value is nearly zero. In order to maintain thermal state of raceway constant to the other cases (consistent evaluation standard), raceway combustions of carbon are greatly increased through adopting pure oxygen blast and increasing oxygen inflow rate, which creates more descending space for solid burdens. Consequently, descent rate of solids is evidently accelerated and more solid burdens are possible to be charged into the furnace in unit time. With remarkable increase in solid charging rate, bigger heat requirements are necessary for heating and reduction of solid burdens in the shaft, especially for endothermic reactions of CCB carbon reduction and sinter hydrogen reduction. As a result, heat flow ratio tends to increase, resulting in very low temperature level in the shaft and insufficient heating-up of burdens. On the other hand, heat demands for direct reduction, solution loss and silicon transfer reactions are evidently reduced in the lower zone. Strong heat transfer occurs between hot gas and solid phase, generating steep temperature gradient. For SI-TI case, the temperature in shaft is a little recovered due to the heat brought by shaft injection gas. However, the low temperature level is still shown in the whole furnace, as analyzed in TI case. Additionally, the height of cohesive zone shows little changes compared with TI case, which is because available heat from shaft injection is nearly counterbalanced by the increased heat requirements for heating-up and reduction of solid burdens (bigger solid charging rate) in the shaft.

Figure 5 shows the variations of $\mathrm{CO}$ concentration with plastics injection and top gas recycling. In all four cases, $\mathrm{CO}$ gas predominantly flows through the regions near central axis and near wall due to larger voidages corresponding to higher volume fraction of coke. Compared with standard operation, $\mathrm{CO}$ concentration shows a little decrease in CCB20-PLA due to lower content of carbon in plastics and increased nitrogen concentration in blast. On the other hand, $\mathrm{CO}$ concentration shows obvious increase in TI case due to tuyere injection of reducing gas and no nitrogen from the blast. In-furnace $\mathrm{CO}$ concentration is enhanced more remarkably in SI-TI case owing to simultaneous ef- 


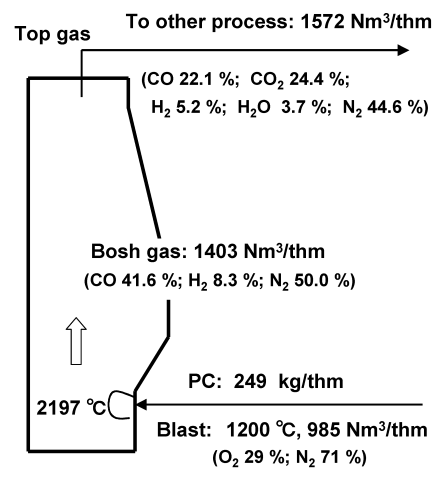

a) Base

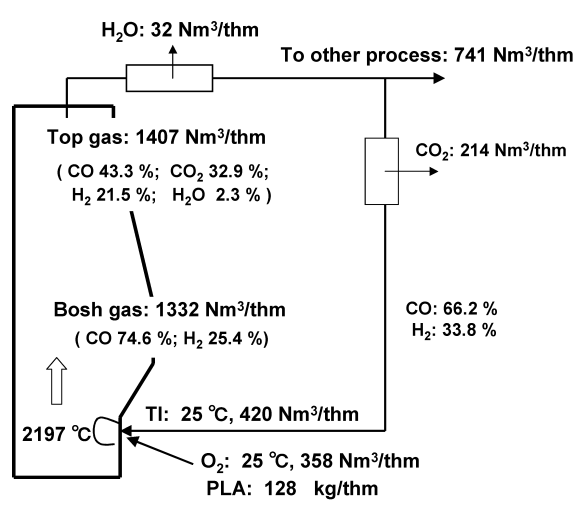

c) $\mathrm{TI}$

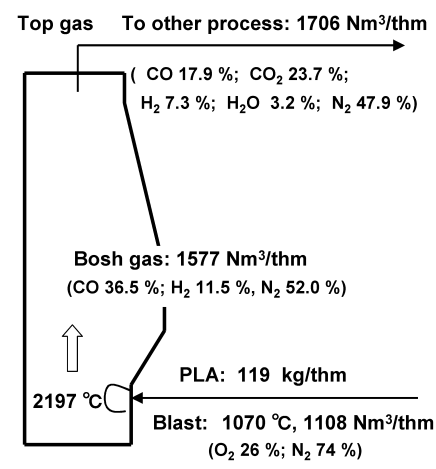

b) CCB20-PLA

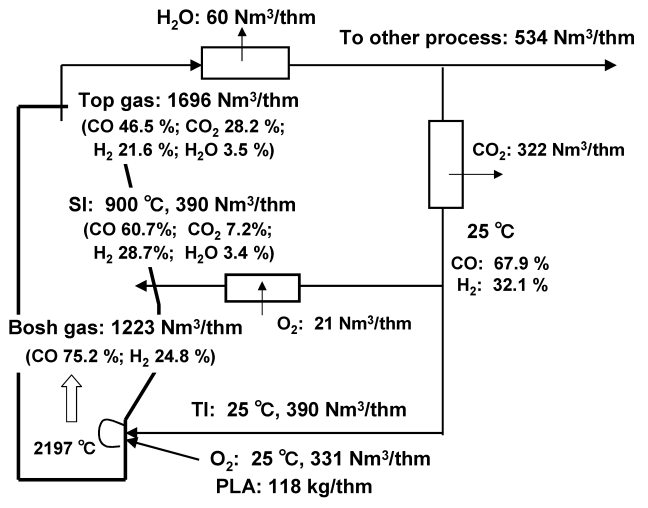

d) SI-TI

Fig. 3. Mass balance of gas in Base, CCB20-PLA, TI and SI-TI cases.

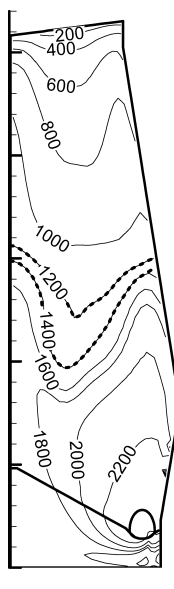

Base

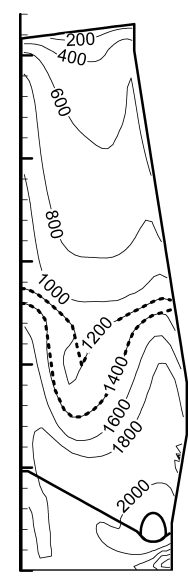

CCB20-PLA

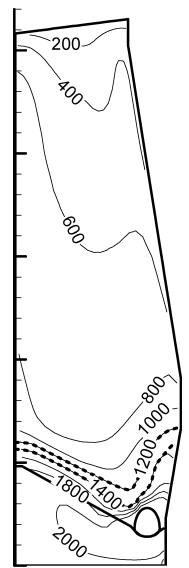

TI

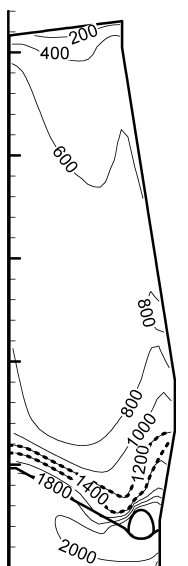

SI-TI

Fig. 4. The distributions of in-furnace solid temperature $\left[{ }^{\circ} \mathrm{C}\right]$.

fects of tuyere and shaft injections. In the last two cases, the CO concentration nearly exceeds $40 \%$ in the whole furnace and the highest value reaches $75 \%$.

Figure 6 shows the distributions of $\mathrm{H}_{2}$ concentration for four evaluation cases. $\mathrm{H}_{2}$ concentration increases a little in CCB20-PLA case. However, more remarkable increase in $\mathrm{H}_{2}$ molar concentrations is estimated in total furnace for TI and SI-TI cases, especially in shaft region of the latter. Due to high hydrogen contents in plastics, hydrogen gas is enriched in the furnace with plastics injection compared with conventional operation. Of course, higher hydrogen concentration is available with recirculation of top gas $\mathrm{H}_{2}$ compo-

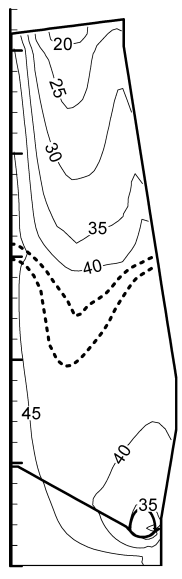

Base

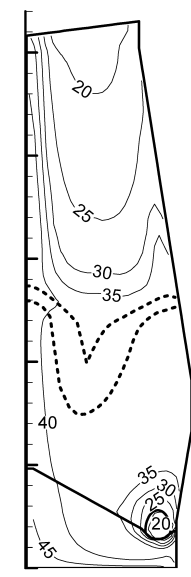

CCB20-PLA

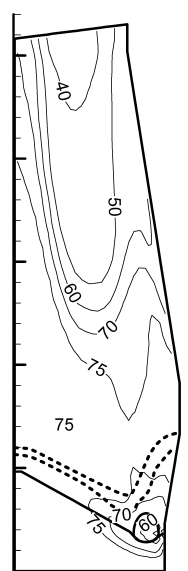

TI

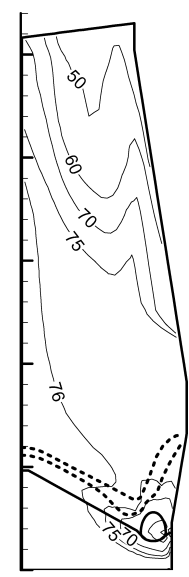

SI-TI
Fig. 5. The distributions of $\mathrm{CO}$ concentration [mol\%].

nent through tuyere and/or shaft injections.

Figure 7 shows the reduction of sinter. In each case, faster reduction rate is predicted in the regions near central axis and wall compared with the other regions due to comparatively favorable reaction conditions including reducing gas concentration and the temperature. In CCB20-PLA case, the reduction of sinter is carried out faster than that in base case and it nearly completes before melting, which is due to the enhancement of $\mathrm{H}_{2}$ concentration and lower solid charging rate. In TI case, the reduction rate of sinter is much faster due to simultaneous increase in $\mathrm{H}_{2}$ and $\mathrm{CO}$ concentrations despite lower temperature level, and even 


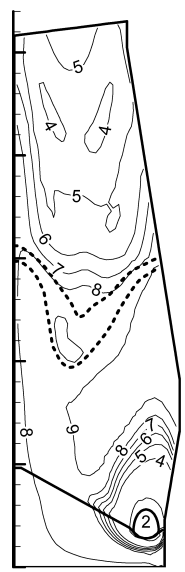

Base

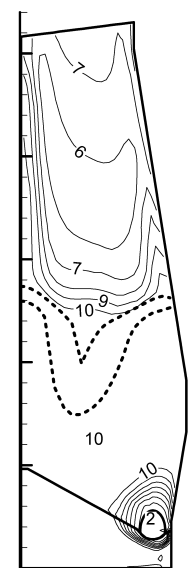

CCB20-PLA

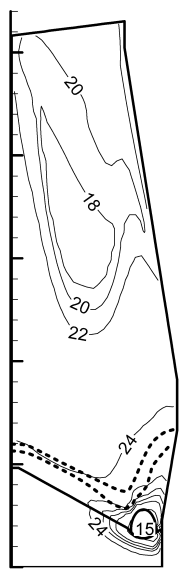

$\mathrm{TI}$

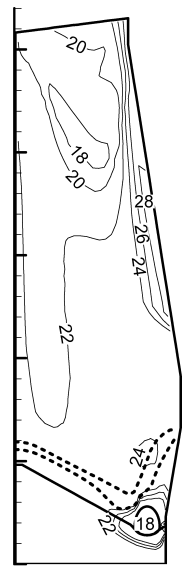

SI-TI

Fig. 6. The distributions of $\mathrm{H}_{2}$ concentration [mol\%].

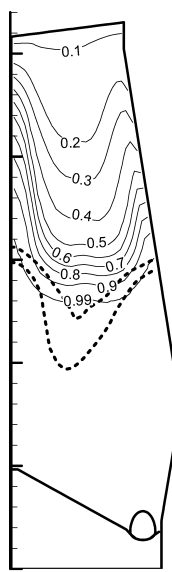

Base

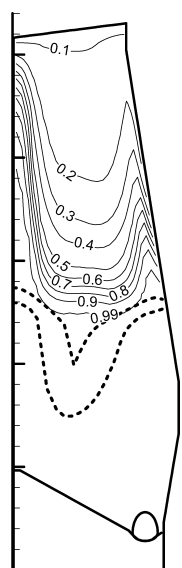

CCB20-PLA

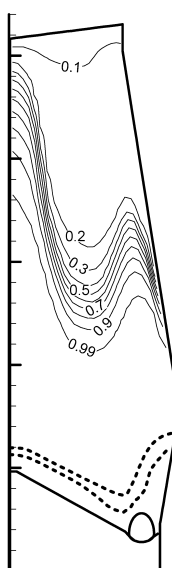

$\mathrm{TI}$

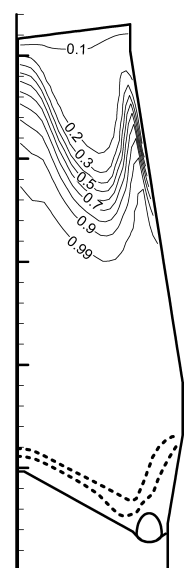

SI-TI

Fig. 7. The distributions of overall reduction degree of sinter $[-]$.

overall reduction completed before reaching $800^{\circ} \mathrm{C}$ isothermal zone. Additionally, in SI-TI case the improvement of sinter reduction in shaft is much more remarkable, directly resulted from shaft injection heat and higher reducing gas concentrations.

Figure 8 shows the reduction of CCB. In CCB20-PLA, the reduction of $\mathrm{CCB}$ is nearly finished before reaching cohesive zone. In TI and SI-TI cases, the reduction of CCB is strongly retarded but it almost completes before full melting. This delay in CCB reduction is because in-furnace temperature level tends to further lower and the surrounding reducing gas atmosphere has little effects on CCB reduction.

\subsection{Variations of Operational Parameters}

The information of primary operation parameters is summarized in Table 5.

The first is about changing tendency of productivity. Compared with base case, the predicted productivity tends to decrease by $10.9 \%$ in CCB20-PLA case. However, it shows an increase by $5.5 \%$ in TI case, and bigger increase by $14.0 \%$ in SI-TI case. The following is the detailed explanations through analyzing effects of oxygen inflow rate and mass ratio of iron bearing burdens to coke.

In CCB20-PLA case, oxygen enrichment in the blast

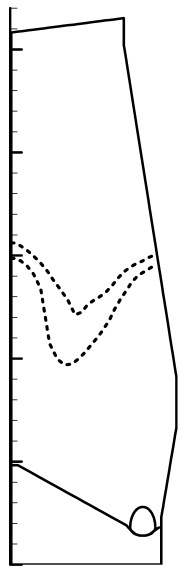

Base

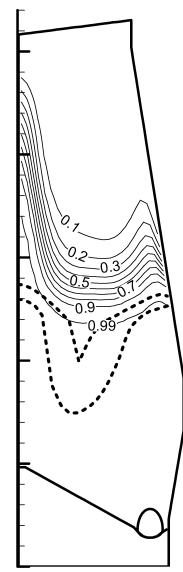

CCB20-PLA

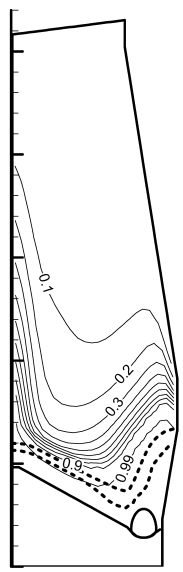

$\mathrm{TI}$

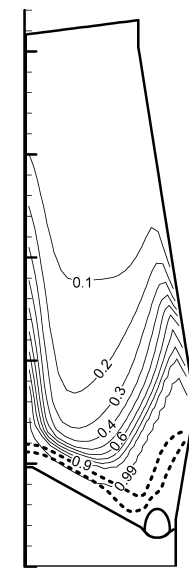

SI-TI
Fig. 8. The distributions of $\mathrm{CCB}$ reduction degree $[-]$.

Table 5. Predicted operation parameters.

\begin{tabular}{|c|c|c|c|c|}
\hline Item & Base & CCB20-PLA & $\mathrm{TI}$ & SI-TI \\
\hline Productivity & 8332 & 7421 & 8789 & 9500 \\
\hline$[\mathrm{kg} / \mathrm{thm}]$ & 518 & 487 & 540 & 505 \\
\hline Coke rate & 269 & 304 & 347 & 321 \\
\hline PC/PLA rate & 249 & 119 & 128 & 118 \\
\hline Carbon in CCB & 0 & 64 & 65 & 65 \\
\hline Top gas CO efficiency & 52.5 & 51.9 & 43.2 & 37.7 \\
\hline Top gas $\mathrm{H}_{2}$ efficiency & 41.9 & 30.2 & 9.7 & 14.0 \\
\hline Corrected CO efficiency** [\%] & --- & --- & 71.8 & 60.9 \\
\hline Corrected $\mathrm{H}_{2}$ efficiency** [\%] & --- & --- & 16.8 & 27.2 \\
\hline C emission rate & 392 & 380 & 313 & 225 \\
\hline Total heat input & 6.10 & 5.95 & 5.23 & 5.33 \\
\hline
\end{tabular}

** Corrected top gas $\mathrm{CO}$ and $\mathrm{H}_{2}$ efficiency:

$$
\begin{aligned}
& \eta_{\mathrm{CO}}^{*}=\frac{m_{\mathrm{CO}_{2}, \mathrm{TG}}-m_{\mathrm{CO}_{2}, \mathrm{Tl}}-m_{\mathrm{CO}_{2}, \mathrm{SI}}}{m_{\mathrm{CO}_{2}, \mathrm{TG}}-m_{\mathrm{CO}_{2}, \mathrm{TI}}-m_{\mathrm{CO}_{2}, \mathrm{SI}}+\frac{M_{\mathrm{CO}_{2}}}{M_{\mathrm{CO}}}\left(m_{\mathrm{CO}, \mathrm{TG}}-m_{\mathrm{CO}, \mathrm{TI}}-m_{\mathrm{CO}, \mathrm{SI}}\right)} \quad\left(\frac{\mathrm{kmol}}{\mathrm{kmol}}\right) \\
& \eta_{\mathrm{H}_{2}}^{*}=\frac{m_{\mathrm{H}_{2} \mathrm{O}, \mathrm{TG}}-m_{\mathrm{H}_{2} \mathrm{O}, \mathrm{TI}}-m_{\mathrm{H}_{2} \mathrm{O}, \mathrm{SI}}}{m_{\mathrm{H}_{2} \mathrm{O}, \mathrm{TG}}-m_{\mathrm{H}_{2} \mathrm{O}, \mathrm{TI}}-m_{\mathrm{H}_{2} \mathrm{O}, \mathrm{SI}}+\frac{M_{\mathrm{H}_{2} \mathrm{O}}}{M_{\mathrm{H}_{2}}}\left(m_{\mathrm{H}_{2}, \mathrm{TG}}-m_{\mathrm{H}_{2}, \mathrm{TI}}-m_{\mathrm{H}_{2}, \mathrm{SI}}\right)} \quad\left(\frac{\mathrm{kmol}}{\mathrm{kmol}}\right)
\end{aligned}
$$

tends to lower in comparison with base case while blast rate is almost the same. Thus, oxygen inflow rate decreases and solid charging rate decreases. Furthermore, the $\mathrm{O} / \mathrm{C}$ ratio decreases due to lower injectant rate of plastics. Eventually, the productivity tends to lower.

In TI case, oxygen inflow rate is evidently increased in order to intensify raceway combustion and maintain constant thermal state of raceway (consistent evaluation standard). That is to say, under the premise that raceway temperature and bosh gas flow rate are kept constant, raceway combustions of coke evidently increases, which lead to bigger solid charging rate and make it possible to improve the productivity. During the preliminary model computations, when the $\mathrm{O} / \mathrm{C}$ ratio was kept constant as that of conventional operation (base case), the calculated in-furnace temperature was much lower than that in Fig. 4, the isotherms drastically shifted downward and hot metal temperature was far lower than the reference value in base case. So that, the model simulation predicted that the blast furnace operation was impossible. Obviously, more coke combustions are 
Table 6. Some computation results in CCB20-PLA and SI-TI cases.

\begin{tabular}{|ll|c|c|}
\hline \multicolumn{2}{|c|}{ Item } & CCB20-PLA & SI-TI \\
\hline Total heat supply from raceway & {$[\mathrm{MJ} / \mathrm{s}]$} & 511 & 532 \\
\hline Oxygen rate & {$\left[\mathrm{Nm}^{3} / \mathrm{s}\right]$} & 24.7 & 36.4 \\
\hline Solid charging rate & {$[\mathrm{kg} / \mathrm{s}]$} & 164.4 & 215.2 \\
\hline Solid heat transfer from gas & {$[\mathrm{MJ} / \mathrm{s}]$} & 54.9 & 70.5 \\
\hline Heat for burdens reductions & {$[\mathrm{MJ} / \mathrm{s}]$} & 76.5 & 113.0 \\
\hline Top gas temperature & {$\left[{ }^{\circ} \mathrm{C}\right]$} & 203 & 198 \\
\hline Heat outflow by top gas & {$[\mathrm{MJ} / \mathrm{s}]$} & 48.5 & 61.3 \\
\hline Heat loss from wall & {$[\mathrm{MJ} / \mathrm{s}]$} & 28.2 & 22.1 \\
\hline
\end{tabular}

Table 7. Calculated reaction rate of sinter indirect reduction.

\begin{tabular}{|c|c|c|c|c|c|}
\hline Reaction & \multicolumn{2}{|c|}{ Reductant \& Case } & $\begin{array}{l}\text { Temp. } \\
{\left[{ }^{\circ} \mathrm{C}\right]}\end{array}$ & $\begin{array}{l}\text { Concentration } \\
\text { [mol-\%] }\end{array}$ & $\begin{array}{c}\text { Reaction rate } \\
{\left[\mathrm{kmol} / \mathrm{m}^{3} . \mathrm{s}\right]}\end{array}$ \\
\hline \multirow{4}{*}{$\mathrm{Fe}_{3} \mathrm{O}_{4} \rightarrow \mathrm{FeO}$} & \multirow{2}{*}{$\mathrm{H}_{2}$} & CCB20-PLA & 800 & 6.0 & 0.0004 \\
\hline & & SI-TI & 600 & 18.0 & 0.0012 \\
\hline & \multirow{2}{*}{$\mathrm{CO}$} & CCB20-PLA & 800 & 28.0 & \multirow{2}{*}{0.0001} \\
\hline & & $\mathrm{SI}-\mathrm{TI}$ & 600 & 60.0 & \\
\hline \multirow{4}{*}{$\mathrm{FeO} \rightarrow \mathrm{Fe}$} & \multirow{2}{*}{$\mathrm{H}_{2}$} & CCB20-PLA & 1000 & 8.0 & \multirow{2}{*}{0.0025} \\
\hline & & SI-TI & 700 & 22.0 & \\
\hline & \multirow{2}{*}{$\mathrm{CO}$} & CCB20-PLA & 1000 & 35.0 & \multirow{2}{*}{0.0008} \\
\hline & & SI-TI & 700 & 70.0 & \\
\hline
\end{tabular}

necessary to provide the sufficient heat, considering the following factors: 1) in TI case injectant rate greatly decreases down to $119 \mathrm{~kg} /$ thm plastics compared with $249 \mathrm{~kg} / \mathrm{thm}$ pulverized coal in base case; 2) no sensible heat of blast is available in TI case due to cold blasting. In order to ensure the operation feasible and compare operation efficiency with other cases at the same product conditions, it is expected to keep hot metal temperature constant as the reference value of base case. For this, the $\mathrm{O} / \mathrm{C}$ ratio was remarkably reduced in TI case despite the possible increase caused by less heat outflow of top gas, decreased heat loss through wall and lowered heat demands for solution loss, direct reduction and silicon transfer reactions. The evident decrease in the $\mathrm{O} / \mathrm{C}$ ratio made the productivity decrease. Eventually, the productivity shows improvement by $5.5 \%$ in TI case compared with base case, which is attributed to bigger charging rate of solid burdens caused by more oxygen inflow rate. In the other hand, the improvement is not so remarkable due to the decrease in the $\mathrm{O} / \mathrm{C}$ ratio.

Regarding SI-TI case with simultaneous shaft and tuyere injections, model simulation predicted more remarkable increase in the productivity. Besides bigger solid rate caused by the same factors as that in TI case, another important factor is that the $\mathrm{O} / \mathrm{C}$ ratio is possible to increase on basis of TI case due to the supplemental heat from shaft injection.

The next is about the variation of reducing agent rate (RAR). The calculation results reveal that: in the cases of CCB20-PLA, TI and SI-TI, injectant rate tends to obviously decrease while carbon in CCB increases with $\mathrm{CCB}$ charging. Additionally, coke rate tends to remarkably increase by $12.6 \%, 28.5 \%$ and $18.9 \%$, respectively. Generally, the RAR shows different changing tendencies. RAR decreases by $6.2 \%$ in CCB20-PLA case, and it shows a little increase by $3.8 \%$ in TI case while tends to decrease by $2.9 \%$ in SI-

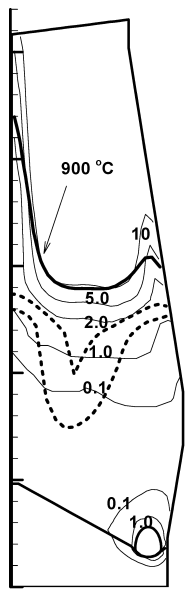

CCB20-PLA

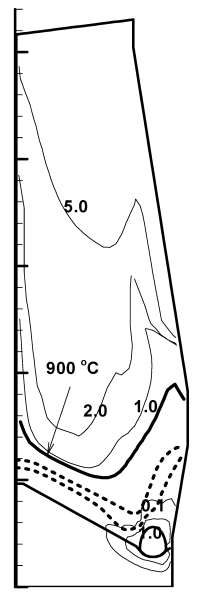

SI-TI
Fig. 9. The distributions of $\mathrm{CO}_{2}$ concentration [mol\%] and solid temperature.

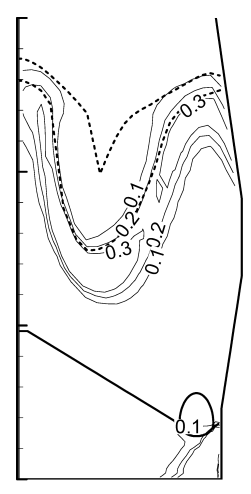

CCB20-PLA

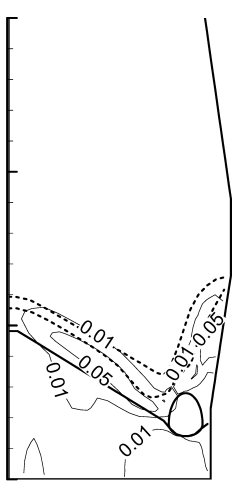

SI-TI
Fig. 10. The distributions of $\mathrm{SiO}$ concentration [mol\%].

TI case. These phenomena are explained as follows. In the three cases except base case, injection rate of waste plastics is deliberately maintained at about $120 \mathrm{~kg} / \mathrm{thm}$, which is far lower than the injection rate of pulverized coal. Furthermore, there is hardly sensible heat from blast in the last two cases. Thus, coke rate is obviously increased to provide sufficient heat. On the other hand, RAR shows decrease in CCB20-PLA case just owing to CCB charging and acceleration of sinter reduction with more involvement of hydrogen in indirect reduction under plastics injection. For TI case, the estimated RAR shows a little increase despite the evident decrease in direct reduction and solution loss reactions. This is attributed to increased coke rate and worsened utilization efficiency of $\mathrm{CO}$ and $\mathrm{H}_{2}$ gas. Finally, in SI-TI case RAR tends to decrease compared with TI case and even base case due to supplementary heat from shaft injection.

According to simulation results, top gas $\mathrm{CO}$ efficiency tends to decrease by $0.6 \%, 9.3 \%$ and $14.8 \%$, and $\mathrm{H}_{2}$ efficiency shows remarkable decrease by $11.7 \%, 32.2 \%$ and $27.9 \%$ with respect to CCB20-PLA, TI and SI-TI cases, respectively. In CCB20-PLA case, CO efficiency shows little change because $\mathrm{CCB}$ carbon reduction worsens the $\mathrm{CO}$ utilization $^{23)}$ while the decrease in direct reduction and solution loss reactions will improve it. In the cases of TI and SI$\mathrm{TI}$, the lowered in-furnace temperature level and increased $\mathrm{CO}$ flow rate lead to poorer CO utilization. On the other 
hand, evident decrease of hydrogen efficiency in all the three cases except reference operation is attributed to the great decrease in temperature level and remarkable increase in hydrogen flow rate. Finally, if the recirculated gas through shaft and/or tuyere injections is taken into account, corrected $\mathrm{CO}$ efficiency shows remarkable improvement in TI and SI-TI cases compared with base case. Corrected $\mathrm{H}_{2}$ efficiency also shows a certain recovery but it is still lower than that in base case. Therefore, model calculation predicted poor utilization of hydrogen gas under the operation with top gas recycling. Some counter-measures are needed to enhance reducing gas utilization, such as controlling burdens distribution and improving thermal conditions in shaft region.

The calculated $\mathrm{C}$ emission rate tends to decrease by $3.1 \%, 20.2 \%$ and $42.6 \%$ corresponding to CCB20-PLA, TI and SI-TI cases, respectively. The common reason is due to the enhancement of sinter hydrogen reduction under waste plastics injection and/or recirculation of top gas hydrogen. On the other hand, the fixing of $\mathrm{CO}_{2}$ also contributes a significant decrease in carbon emission.

Finally, it is about the estimated heat input per production. Total input heat $[\mathrm{GJ} / \mathrm{thm}]$ tends to decrease by $2.5 \%$, $14.3 \%$ and $12.6 \%$, respectively in the last three cases. Under the operation with CCB charging, waste plastics injection, and/or top gas recycling, lower energy consumption is achieved owing to the following factors: 1) top gas heat outflow decreases due to lowered top gas temperature; 2) heat loss through furnace wall decreases due to the smaller temperature driving-force caused by lower temperature level inside the furnace; 3 ) heat demand for solution loss reaction directly attributed to the decrease of $\mathrm{CO}_{2}$ concentration in the high temperature region; 4) heat demand for direct reduction reaction since indirect reduction of sinter is accelerated in the shaft due to high reducing gas potentials, especially enhancement of hydrogen reduction; 5) heat demands for silicon transfer reactions is also reduced mainly due to the narrowing of high temperature zone. The variations of these items are explained in details in Sec. 3.4. That is to say, total heat input, which takes into account blast heat and combustion heat, tends to decrease in CCB20-PLA, TI and SI-TI cases. As shown in Table 5, more remarkable decrease in heat input is shown in the last two cases of TI and SI-TI cases, which is because wall heat loss, heat consumptions by solution loss and silicon transfer reactions show greater decrease compared with base and CCB20-PLA cases. Additionally, in TI case total heat input shows obvious decrease despite the increase in reducing agent rate. This is because sensible heat of blast is hardly available and nearly all heat supply is got from raceway combustions. At last, the heat efficiency in SI-TI case is a little lower than that in TI case because heat outflow by top gas and heat loss through wall comparatively increase with shaft injection.

\subsection{Discussions}

The model simulations predicted higher efficiency under the operation with top gas recycling. The mechanisms are illustrated through comparing simulation results between CCB20-PLA and SI-TI cases.

Table 6 lists some computation data in the cases of
CCB20-PLA and SI-TI. In SI-TI case, oxygen rate increases by $47 \%$ compared with CCB20-PLA case, and solid charging rate increases by $30.9 \%$. As a result, the heat consumed by heating and reductions of solid burdens in the shaft are increased by $28.4 \%$ and $47.7 \%$. Obviously, shaft temperature tends to decrease since total heat supply from raceway shows no big difference in these two cases. Then, this temperature decrease will lead to the decrease in heat outflow by top gas and heat loss from wall. In SI-TI case, top gas temperature shows not-so-remarkable decrease while top gas heat outflow increases in comparison with CCB20-PLA case, which is because shaft injection increases heat supply and gas flow rate. However, the top gas temperature $\left(198^{\circ} \mathrm{C}\right)$ is still lower than that in base case $\left(242^{\circ} \mathrm{C}\right)$.

Table 7 shows calculated reaction rate of sinter indirect reduction corresponding to CCB20-PLA and SI-TI cases. Model computations reveal that: for reduction of magnetite and wustite, enhancement of $\mathrm{CO}$ and $\mathrm{H}_{2}$ molar concentration in gas phase can also ensure equivalent or faster reaction rate under lower reaction temperature. In SI-TI case, reducing gas potential is enhanced with reducing gas recirculation and plastics injection, the reduction of sinter is remarkably accelerated in the upper shaft region and overall reduction is faster completed despite the remarkable decrease in shaft temperature. Consequently, endothermic direct reduction reaction notably decreases.

Figure 9 shows the distributions of $\mathrm{CO}_{2}$ molar concentration and solid temperature. In SI-TI case, lower concentration of carbon dioxide is generated in the lower zone due to faster reduction of sinter in upper shaft region. Furthermore, high temperature zone (over $900^{\circ} \mathrm{C}$ ) is evidently narrowed. As a result, solution loss reaction greatly decreases compared with CCB20-PLA case.

Figure 10 shows the distributions of $\mathrm{SiO}$ molar concentration in gas phase. The transfer of silicon is considered to carry out through the following two routes: $\mathrm{SO}_{2}$ (coke) $\rightarrow \mathrm{SiC}($ coke $) \rightarrow \mathrm{SiO}($ gas $) \rightarrow \mathrm{Si}$ (hot metal) and $\mathrm{SO}_{2}$ ( (lag) $\rightarrow$ $\mathrm{SiO}$ (gas) $\rightarrow \mathrm{Si}$ (hot metal). The lowering of in-furnace temperature level and the narrowing of high temperature zone reduce the generation of $\mathrm{SiO}$ gas and restrain silicon transfer reaction. The predicted silicon content in hot metal is 0.5 and 0.1 corresponding to CCB20-PLA and SI-TI cases, respectively.

Under operation with top gas recycling, carbon composite agglomerates charging and waste plastics injection, the decrease in heat outflow by top gas, wall heat loss and heat demands for direct reduction, solution loss and silicon transfer reactions, contribute to improve the efficiency of blast furnace.

\section{Conclusions}

The blast furnace operations with top gas recycling, carbon composite agglomerates charging, cold oxygen blast and waste plastics injection are numerically evaluated by means of multi-fluid blast furnace model and compared with conventional operation. The simulation results reveal that $\mathrm{CCB}$ charging and/or cold oxygen blast lead to very low temperature level in the shaft, which retards the reduction of CCB. On the other hand, injection of waste plastics 
enriches hydrogen in the furnace. If top gas recycling with $\mathrm{CO}_{2}$ removal is further adopted, concentrations of $\mathrm{H}_{2}$ and $\mathrm{CO}$ are tremendously enhanced in the whole furnace, which greatly accelerates the reduction of sinter in the shaft in spite of lower temperature. Under the innovative operations, the efficiency of blast furnace shows evident improvement, especially in the case with simultaneous injections of treated top gas into shaft and tuyere. Total heat input per production decreases while the productivity increases. Additionally, top gas recycling and waste plastics injection contribute to reduce carbon dioxide emission considerably. It is possible to realize high efficiency operation of blast furnace with improved productivity and lowered environment load through applying the processes presented in this study.

\section{REFERENCES}

1) S. Hosoki: ISIJ Int., 33 (1993), 44.

2) METI: Oil Consumption Statistics, Ministry of Economy, Trade and Industry, Tokyo, (2002).

3) A. I. Babich, H. W. Gudenau, K. T. Mavrommatis, C. Froehling, A. Formoso, A. Cores and L. Garcia: Rev. Metal., 38 (2002), 289.

4) Y. Ohno, M. Matsuura, H. Mitsufuji and T. Furukawa: ISIJ Int., 32 (1992), 838.

5) M. A. Tseitlin, S. E. Lazutkin, and G. M. Styopin: ISIJ Int., 34
(1994), 570

6) M. Qin and N. Yang: Scand. J. Metall., 15 (1986), 138.

7) F. Fink: Proc. European Ironmaking Cong., VDEh, Düsseldorf, (1986), PV-3.

8) W. K. Lu and R. V. Kumar: ISS Trans., 5 (1984), 25.

9) P. R. Austin, H. Nogami and J. Yagi: ISIJ Int., 38 (1998), 239.

10) T. Ariyama, M. Sato and R. Murai: Private communication.

11) R. Murai, M. Sato and T. Ariyama: Proc. Science and Technology of Innovative Ironmaking for Aiming at Energy Half Consumption, ISIJ, Tokyo, (2003), 205.

12) R. Murai, M. Sato and T. Ariyama: CAMP-ISIJ, 15 (2002), 859.

13) H. Komiyama: The Handbook on Global Warming Problems, IPC, Tokyo, (1992).

14) H. W. Gudenau, D. Senk, A. Babich, C. Frohling, O. S. Kweon, S. Wang and T. Wieting: Proc. Science and Technology of Innovative Ironmaking for Aiming at Energy Half Consumption, ISIJ, Tokyo, (2003), 21.

15) P. R. Austin, H. Nogami and J. Yagi: ISIJ Int., 38 (1998), 246.

16) P. R. Austin, H. Nogami and J. Yagi: ISIJ Int., 37 (1997), 748.

17) J. A. Castro, H. Nogami and J. Yagi: ISIJ Int., 42 (2002), 44.

18) J. A. Castro, H. Nogami and J. Yagi: ISIJ Int., 40 (2000), 637.

19) H. Nogami: Tetsu-to-Hagané, 89 (2003), 212.

20) A. Kasai, Y. Matsui, F. Noma, H. Iwakiri and M. Shimizu: Tetsu-toHagané, 87 (2001), 313.

21) A. Kasai, Y. Matsui and K. Yamagata: CAMP-ISIJ, 16 (2003), 95.

22) M. Asanuma, T. Ariyama, M. Sato, R. Murai, T. Nonaka, I. Okochi, H. Tsukiji and K. Nemoto: ISIJ Int., 40 (2000), 244.

23) M. Chu, H. Nogami and J. Yagi: ISIJ Int., 44 (2004), 510.

24) M. Chu, H. Nogami and J. Yagi: ISIJ Int., 44 (2004), 801. 